\title{
Un siglo, una década y un año de Carlo Michelstaedter.
}

\section{A century, a decade and a year of Carlo Michelstaedter.}

DOI: $10.32870 /$ sincronia.axxv.n80.8b21

\author{
Gabriel Adelio Saia \\ Universidad Nacional de San Martín (ARGENTINA) \\ CE: gabriel.saia92@gmail.com/ID ORCID: 0000-0002-5116-9741
}

Esta obra está bajo una Licencia Creative Commons Atribución-NoComercial 4.0 Internacional

Recibido: 31/03/2021

Revisado: 04/05/2021

Aprobado: $25 / 05 / 2021$

\section{RESUMEN}

Carlo Michelstaedter (Gorizia, 1887-1910) dejó una estela singular en la filosofía italiana de principios del S. XX. A casi ciento once años de su fenecimiento, de su suicidio, todavía se puede discutir la influencia del pensador italiano, la vitalidad de sus tópicos y la profundidad de su pensamiento. Nuestro propósito será conocer la figura que subsiste detrás del pensador de La persuasión y la retórica. En virtud de este objetivo, realizaremos un recorrido por su obra filosófica, epistolar y poética, que sin dudas no basta; sin embargo, nos ayudará a echar luz sobre la fascinante creación del último médico del nihilismo, el último gran diagnóstico de la honda falta de sentido que acarreó la segunda parte del S. XIX e inauguró la primera década del S. XX. Al modo de una elegía, quizá también de una oda, recordaremos al filósofo italiano en estos tiempos, ya que sigue siendo una empresa fructífera, inacabada y sumamente misteriosa. En conclusión, intentaremos defender a Michelstaedter de las lecturas meramente suicidas y nos aproximaremos hacia una interpretación en cuatro tiempos del filósofo italiano.

Palabras claves: Persuasión. Retórica. Nihilismo. Pesimismo. Suicidio. Michelstaedter. 


\section{ABSTRACT}

Carlo Michelstaedter (Gorizia, 1887-1910) left a singular trail in the Italian philosophy of the early 20th century. Almost one hundred and eleven years after his demise, his suicide, one can still discuss the influence of the Italian thinker, the vitality of their topics and the depth of their thinking. Our purpose is to know the figure that subsists behind the thinker of Persuasion and Rhetoric. In accordance with this objective, we will make a tour of his philosophical, epistolary and poetic work, which is certainly not enough. However, it will help us to shed light on the fas-cinating creation of the last doctor of nihilism, the last great diagnosis of the profound lack of sense that carried the second part of the S. XIX and inaugurated the first decade of the S. XX. In the form of an elegy, perhaps even an ode, we will remember the Italian philosopher in these times, for he remains a fruitful, unfinished and extremely mysterious undertaking. In conclusion, we will try to defend Michelstaedter from merely suicidal readings and approach a four-time interpretation of the Italian philosopher.

Keywords: Persuasion. Rhetoric. Nihilism. Pessimism. Suicide. Michelstaedter.

II ne faut pas abandonner le suicide à des gens malheureux qui risquent de le gâcher et d'en faire une misère ${ }^{1}$ “Un plaisir aussi simple”, Michel Foucault, 1979, p. 779

\section{Introducción}

Carlo Michelstaedter nació en Gorizia el 3 de junio de 1887. Veintitrés años más tarde, el 17 de octubre de 1910, alojado brevemente en su hogar natal encuentra el horizonte de su Vida, la infinitud lo acecha y decide responder al llamado de una teoría que es solo teoría en tanto que acción. La búsqueda del absoluto se vuelve sobre sí, es tangible, es experiencia: “L'assoluto non l’ho mai conosciuto, ma lo conosco così come chi soffre d'insonnia conosce il sonno, come chi guarda l'oscurità conosce la luce"2 (Michesltaedter, 1995, p. 55). Pero su juventud no debe crear en nosotros un prejuicio, sino más bien una risotada, una asombrosa curiosidad y una seriedad

\footnotetext{
1 "No debemos abandonar el suicidio a personas infelices que corren el riesgo de estropearlo y convertirlo en una miseria". *A menos que se indique lo contrario, las traducciones son propias.

2 "No conocí el absoluto, pero sí lo sé. Lo sé como quien sufre de insomnio y conoce el sueño, como aquel que, por mirar en la oscuridad, conoce la luz"
} 
crepitante. Por simple azar, Michelstaedter perteneció a una generación de supuestos "suicidas precoces", si cabe mencionar esta tautología, integrada por otros dos genios fugaces, como fueron Otto Weininger y George Trakl. La proximidad geográfica también ha de añadir un elemento para quienes gustan de realizar dicha comparación, aunque el paisaje descripto por el triestino en su copiosa correspondencia siempre nos remite a parajes bellos y familiares. ¿Qué nos queda? Acaso, ¿trazar un recorrido cronológico, una suerte de biografía de relaciones de Carlo Michelstaedter? ¿Hacer un panegírico diferido por un espacio que excede el siglo de duración? ¿Tratar dos o tres de sus conceptos claves para la historia de la filosofía? ¿Hablar sobre su ejemplar Muerte? Ninguno de estos interrogantes es necesario, pero tampoco ellos son inoportunos en esta situación para profundizar en la figura que Michelstaedter nos ofrece, más allá de su Muerte, como si en una sesión de espiritismo - que es lo que hacemos al hacer filosofía- buscásemos la vuelta para extraer aquello que Deleuze pretendió exponer $-\mathrm{y}$ vuelvo al espiritismo- con la "creación de conceptos". Como si se tratara de un juego entre virtualidad y actualidad, conceptos que no se agotan fácilmente, que tienen, en un grado ontológico, una exhaustividad incesante. Todo lo que podamos hacer aquí y ahora corresponderá, como nos recuerda Michelstaedter al leer el prefacio de su tesis doctoral, que es a un tiempo una acusación y una petición de principio, al dominio de la retórica:

[...] lo lo so che parlo perché parlo ma che non persuaderò nessuno; e questa è disonestà ma la rettorica anagkázhei me taûta drân bía - o in altre parole 'è pur necessario che se uno ha addentato una perfida sorba la risputi'3 ${ }^{3}$ (Michelstaedter, 1995, p. 3).

Incluso así, como finalmente lo admite bajo el aspecto trágico: no podemos evadir el veneno que supone la retórica, que supone el lenguaje en su total expresión. "Con le parole guerra alle parole" 4 (Michelstaedter, 1995, p. 134), así empieza el escrito póstumo que es conformado por los apéndices a su gran obra, su tesis de doctorado jamás defendida, La persuasione e la rettorica. Este estudio

\footnotetext{
3 "Sé que hablo porque hablo, pero que no persuadiré a nadie. Esta cuestión es deshonesta, pero la retórica 'me obliga a hacerlo', en otras palabras, 'es necesario que aquel que ha mordido una fruta asquerosa la escupa'"

4 "Con palabras, guerra a las palabras"
} 
supuso un cambio en la vida de Michelstaedter. Así que permitámonos hablar algo acerca de sus orígenes y relaciones, para luego pasar a unos pocos tópicos que articulan su opus magnum y, por último, abordar el "caso" Michelstaedter.

Podemos mencionar de manera un tanto anecdótica que nació en una familia acomodada triestina y hebrea. Sus padres fueron Alberto y Emma, tuvo tres hermanos, Gino, Paula y Elda. De joven fue introvertido y dedicó buena parte de sus ratos a la poesía, la música, el disegno y no mucho más. No sobresalió en primeras letras, así como tampoco al finalizar su instrucción básica, teniendo un desempeño que podríamos llamar "poco satisfactorio". A principios de su vida académica, se trasladó a Viena para estudiar matemáticas, aunque al poco tiempo, en octubre de 1905, se movilizó a Firenze (Michelstaedter, 2010, pp. 26-30) y se apuntó en Lettere en el Istituto di Studi Superiori. Sabemos poco de sus relaciones, más allá de los nombres propios de novias o "amigas", Iolanda De Blasi, Nadia Baraden y Argia Cassini, y alguna correspondencia dirigida a estas; ${ }^{5}$ lo mismo sucede respecto a sus amigos, Enrico Mreule, Nino Paternolli, Gaetano Chiavacci y Vladimiro Arangio-Ruiz. ${ }^{6}$ Es decir, solo podemos recrear relaciones en la medida en que contamos con vastas referencias epistolares y alguna que otra evocación póstuma. ${ }^{7}$ Sin embargo, y atendiendo principalmente a dos momentos cruciales de su vida, podemos precisar un poco más el grueso de sus vínculos. La escritura amistosa, familiar y jovial de Michelstaedter empieza a mostrar su cariz oscuro en un momento preciso, en una carta dirigida a su amigo Chiavacci el 26 de febrero de 1909,

\footnotetext{
${ }^{5}$ Además de una breve novela de ficción pseudobiográfica escrita por el curador de su obra, Sergio Campailla (2010).

${ }^{6}$ Estos últimos oficiarán, además, como sus editores en ocasión de la primera publicación de La persuasione e la rettorica (1913; Genova: Formigini, a cura di V. Arangio-Ruiz) y de la principal recopilación de sus escritos en Opere (1958; Firenze: Sansoni, a cura da Chiavacci). Podemos sumar a estas dos ediciones aquella confeccionada por su primo, Emilio Michelstaedter (1922; Firenze: Vallecchi, a cura da Emilio Michelstaedter), y una última de Maria Raschini (1972). Así, tenemos cuatro ediciones póstumas de La persuasione e la rettorica, hasta que, en las décadas del 70-80, Sergio Campailla realizó la edición crítica del "completo" de su obra poética, filosófica, pictórica y epistolar. Para subvertir estas, y más ceñido a la edición de Chiavacci y al Manoscritto " $C$ ", la edición crítica de Andrea Comincini, editada por Joker en 2015.

${ }^{7}$ Como sucede con las notas dejadas por Emilio, el prefacio a Opere (1958), la primera biografía del goriziano escrita por Campailla (1974).
} 
donde podemos leer: "il mio fratello di New York è morto. - Morto per un maledetto accidente, e ora dopo due settimane non sappiamo niente di più. È da impazzire"8 (Michelstaedter, 2010, p. 372). Teniendo en cuenta que las primeras misivas que tenemos de febrero de 1909 están dirigidas también a Chiavacci, podemos figurarnos que el intercambio con su amigo corresponde tanto a la muerte de su hermano como a la producción de su tesis, de su póstuma obra. Es así que leemos en una carta enviada por Carlo a principios de ese fatídico mes: "Per quello spiraglio della rettorica ho contemplato cose tanto più interessanti -amaramente interessanti che ora mi secca maledettamente limitarmi a quella meschinità - ma: omnia in omni!!... et omnia nihil"9 (Michelstaedter, 2010, p. 370). Pero esta idea se prefiguró en el joven tiempo antes, aproximadamente en mayo del año anterior, cuando le comenta a su padre que, en ocasión de un trabajo filológico escolar, lo único que le interesó fue la relación entre "elocuencia" y "retórica" en la traducción de Brunetto Latini del discurso Pro Q. Ligario Oratio del gran Cicerón (La Rocca, 2011).

Sin dudas, la génesis del texto se revela caótica, no menos sucede con su escritura, y si seguimos la división cronológica que hace Chiavacci de su trabajo en la introducción de Opere (1958), podemos encontrarnos con que los años 1908-1909 corresponderían a una suerte de “assolutto pessimismo" ("pesimismo absoluto") que culmina en 1910, cuando el pensamiento deja de ser teoría para convertirse en "criterio inmanente a la acción, vida en acto" (Michelstaedter, 1958, p. xiv). De esto dan testimonio varias epístolas, como la dirigida a Enrico Mreule el 13 de junio de 1909, donde expone ampliamente su teoría de la gymné psykhé ("alma desnuda"), o la destinada a Chiavacci, del 25 de abril de 1910, donde la fatiga lo lleva a rotular un dibujo de su habitación con una leyenda en griego: "têde dè egò mèn bíon ábion diabióo érgon dè méga phyei"10 (Michelstaedter, C., 2010, p. 463, nota 2). Bastaría dar un "golpe bajo" literario y releer la última carta que le escribió Carlo a su madre, fechada el 10 de septiembre de 1910, donde por la calidad

\footnotetext{
8 "Mi hermano de Nueva York está muerto. Murió en un maldito accidente, y ahora, pasadas dos semanas, no sabemos nada más. Es una locura".

9 "Por la rendija de la retórica contemplé cosas tan interesantes, amargamente interesantes, que ahora me irrita dedicarme solo a esa mezquindad, aunque: itodo está en todo!... y todo es nada".

10 "Acá, donde vivo una vida que no se puede vivir, brota una gran obra".
} 
del escrito se demuestra aquello que Chiavacci menciona al paso: la teoría se vuelve acto, se deja de ver (y de ser espectáculo) para ser. Así como se da por sentado que leemos por propia voluntad, quizá hasta por placer, pero como un acto violento, oímos música sin apenas proponérnoslo y de manera inevitable. Esto es, el paso del theoreîn a la real philosophía, es decir, aquella que se quiere no por sí misma o su amplitud de campo, sino por su acción, por su bien. Asimismo, las relaciones de Carlo están signadas por esta marcada tendencia hacia un querer productivo. De este modo, y para finalizar con el entresijo de las relaciones de Carlo, damos paso a un apartado quizá más conflictivo: la persuasión y la retórica.

\section{II}

En cierto sentido, ya comenzamos a diagramar la estructura principal de la obra: vacilaciones en torno a todo aquello que podemos llamar "inauténtico", "ficticio", "social", enfrentado a lo que decimos "auténtico", "individual” y, en suma, "philosophia perennis". Manifiesta Michelstaedter un ferviente ánimo que se yergue en contra de los modernos y - permítaseme generalizar aquí- los alemanes; ni futurista ni dannunziano, mucho menos hegeliano. Pero tampoco ha de sorprender que no se reconozca nietzscheano, en absoluto. Nietzsche todavía es muy positivo para comprender el valor detrás de su hallazgo, detrás de su crítica al historicismo germano, como realiza en Sobre la utilidad y el perjuicio de la historia para la vida (segunda intempestiva) así como durante el inicio de su vida como autor. No hay un método en Carlo Michelstaedter, y eso es algo sencillamente reprochable, pero sí hay una lucha, una búsqueda, un propósito. No se reconoce moderno y es por esto que no trata a su tiempo con "justicia"; no se reconoce parte del imperio austrohúngaro, no respeta su raíz alemana; no se reconoce retórico, trata de asumir el peso y la propiedad de la persuasión. Si recurrimos a sus escritos, no solo a sus cartas, sino principalmente a La persuasione e la rettorica vamos a encontrar un juego de pastiche, un palimpsesto que aúna varias lenguas y fuentes no solo en su materialidad (italiano, griego, latín, alemán), sino también en su estilo (directo, formal, aliterado, interrumpido, con guiones medios) e intereses (filosofía, poesía, tragedia, matemáticas, química). Resiste a la escritura, la hace turbia y casi ominosa, pero es porque 
la persuasión requiere de eso mismo para no ser retórica. Michelstaedter nos hace pensar en el personaje que hoy es Kafka: un judío checo - por extensión, austrohúngaro- que escribía en alemán a comienzos del Siglo pasado. Pero el crisol se vuelve aún más rico en Carlo (Benvegnù, 2016), donde la experiencia de escritura menor se da a cada paso. No solo porque publicó durante su vida nada más que cuatro menudos artículos periodísticos (uno sin su consentimiento expreso), sino además porque se enfrenta a una doble lejanía: no quiere ser escolar, no quiere ser vulgo. Tenemos que apuntar, también, que su propia Gorizia natal es un mosaico de culturas de la Mitteleuropa rica y tormentosa.

En efecto, la lucha de Michelstaedter se vuelca hacia dos bandas bien separadas. "Retórica" designa todo aquello que nos permite mantenernos en vida; la sociedad, la patria, el orden, las leyes, pero también el trabajo, la filosofía como búsqueda por aumentar el conocimiento, la iglesia con sus rituales, la ciencia y sus sujetos reificados. Con este término podemos entender todo aquello que es impropio, impersonal, obtuso, que se hace siempre con vistas a un futuro y que tiene bien presente un pasado; en suma, todo lo que jamás será un fin. Es lo que vuelve al lenguaje una trampa, ya que en su propósito principal (comunicar=convencer) violenta sus condiciones de posibilidad: se recrea en fórmulas engañosas que buscan un objetivo mezquino.

El modo persuadido evade esta cuestión, porque no se mantiene siquiera en su campo (el campo retórico) sino que opera según otra lógica, la del presente, la del ser consciente y propio. El hombre persuadido ha de establecer una situación donde su comunicación, en lugar del convencimiento, busque algo diverso: es el mensaje de Jesús, de Buda -que jamás escribieron-, aunque también el de Ibsen: no hay que imitar para ser discípulo, el buen discípulo se dedica a seguir. Y es por esto que luego de la cita antes mencionada del prefacio ("lo lo so che parlo...") de su tesis, añade: "Eppure quanto io dico è stato detto tante volte e con tale forza che pare impossibile che il mondo abbia ancor continuato ogni volta dopo che erano suonate quelle parole" (Michelstaedter, 1995, p. 3). Y claro, se refiere a Jesús y Buda, como dije, quienes sucumben en su mensaje frente al edificio teológico, pero también a los griegos clásicos, a Parménides, Heráclito, Empédocles, que formaron un catálogo de naturistas para Aristóteles, y ni hablar de Sócrates o de 
Beethoven, quienes fueron interpretados, devanados y digeridos (sistemáticamente en ambos casos, ya sea según la "tradición" filosófica o el contrapunto).

Así, el persuadido tiene, como figura que traza límites, una conciencia moral que le es propia, abandonando los plexos axiológicos tan caros para la sociedad, para la civilización. Antes el saber y el pensar eran uno y lo mismo, nos dice Carlo. No había un gran armario donde colocar ideas momificadas. Es por esto mismo que la filosofía es concebida como el último de los bastiones de la retórica: Platón y Aristóteles fueron sus principales artífices. Cabe mencionar que el título inicial de su tesis doctoral era I concetti da persuasione e rettorica in Platone ed Aristotele, pretendido trabajo doxográfico, que luego devino en un tratado ontológico, psicológico, social y lingüístico. El pensamiento de Michelstaedter no deja de lado el rol de la filología, en absoluto, menos si uno revisa los Appendici Critiche, lugar en que recoge y comenta pasajes de obras platónicas y aristotélicas, pero sí extiende su trabajo a una tesis imposible, una empresa que él reconoce como tal.

Para redondear, dos modos diversos y antagónicos son los que articulan la posibilidad vital: persuasión y retórica. La tesis apuntaba a problematizar este segundo polo inicialmente, mas luego, decantó hacia el sitio que le corresponde, es decir, el uomo persuaso. ¿Qué clase de trabajo hubiera presentado un verdadero filósofo, según los términos que entiende Michelstaedter? No vale demasiado la pena preguntarnos por un trabajo que no fue, porque hay sobradas lecturas posibles, por más obsidianas y opacas que estas se vean.

III

Algo que vale la pena discutir es “¿por qué Michelstaedter?”. Planteadas en el corpus integrado por La persuasione e la rettorica, los apuntes de Appendici Critiche, la escolaridad de los Scritti Vari y las nociones que deja entrever en Dialogo della salute, podemos ver tesis fortísimas sobre los inicios de un tumultuoso y breve Siglo. Carlo no vio la guerra, no la vivió, no participó de ella; su madre, hermana y otros familiares, sí, en carne propia. Carlo no supo nada del fascismo, a no ser por las ideas de D’Annunzio, autor que seguramente leyó o del cual oyó hablar. Mussolini era unos pocos 
años mayor que Carlo, en 1910 contaba poca relevancia política, y abrigaba más ánimos de reo y nietzscheano -obviamente dannunziano- que de Duce. Es decir, Carlo no vivió más que la decadencia propia de las postrimerías decimonónicas. En pocas palabras, a no ser por los dilemas personales (Nadia B., su hermano, la partida de un amigo para la Argentina), podemos arriesgarnos a pensar que Carlo vivió su vida. Michelstaedter estudió, pensó, escribió incansablemente, entabló amistades y mantuvo amores, pero no tuvo las motivaciones de la generación posterior, o de aquellos que vieron más cantidad de días. Podemos encontrar, sin embargo, profusas ideas que hacen surgir semblantes tales como el de Heidegger, Wittgenstein, Jaspers, Lukács. Nuestro autor presagia, como si se tratara de un profeta, las problemáticas más cruciales de la primera mitad del Siglo: el giro lingüístico, el relativismo científicomoral, la relación del subalterno, la hermenéutica, la fenomenología, la finitud, los modos caídos, el ser-en-el-mundo, el ser-para-la-muerte. Claro está, no se trata de un visionario ni de un intelectual superior - tampoco él lo querría de ese modo-, sino más bien de un philósophos, de un persuadido, de un límite formal en la estructura retórica, un quiebre, un entre. En varios sentidos, Carlo no fue una víctima de su tiempo, sino un doctor que evalúa los síntomas, que opera por sobre las determinaciones del logocentrismo y los problemas acarrea-dos por la phoné (claro está, tiempo antes incluso del nacimiento de Jacques Derrida). Pero, ¿qué se despertó tras su muerte?

Hay un buen artículo de Sergio Campailla (2018), "Las primeras interpretaciones de Michelstaedter (1910-1916)", donde este nos brinda una línea de lectura sumamente clara. Carlo no tuvo un propósito editorial en cuanto tal, no supo ser un ensayista precoz, al modo de Slataper, ni tampoco un joven catedrático como lo fue Nietzsche, pero quienes recogieron sus obras para la publicación post suicidium generaron cierto revuelo alrededor de la figura del joven filósofo. Ya la muerte por mano propia de un veinteañero en el Trieste generó rumores y fervientes apropiaciones, y en su breve escrito Campailla logra dar cuenta de cómo Papini, Cecchi y Borgese fueron los primeros en aducir causas "metafísicas". El joven Papini siquiera había tenido acceso al texto del doctorando goriziano, que no fuera editado hasta dos años luego de la muerte de este último, y es posible que haya realizado una traslación basada en la muerte de Otto Weininger. Por 
su parte, motivados por la novedad de la publicación del primer volumen de poesía de Michelstaedter, los triestinos Slataper y Benco hacen su parte. En este caso el suicidio cobra un cariz diverso: el trabajo lo es todo, la verdad lo es todo. Vale la pena, según su juicio, suicidarse por el trabajo, por el esfuerzo de la verdad. Cosa más insólita es que los paisanos de Michelstaedter apelan de nuevo a la fuente papiniana, a aquel que no leyó siquiera la obra e igualmente aventuró una teoría. Pero estos no fueron los únicos en hablar. Luego de Cecchi y Borgese -que decidimos omitir por la monotonía de sus hipótesis-, Amendola ve el pasaje del theorein al aggire, del dicho (visto) al hecho (oído) como un motivo suficiente (Campailla, 2018).

Pero eso no es todo, ya que basta con volver la vista un poco hacia nuestros días para descubrir un artículo revelador en este sentido: "Sobre el suicidio lógico" de Miguel Morey (2014). Aquí se ensaya una vuelta a los conceptos de "metafísico" y "lógico" como adjetivos del acto suicida. Inspirado por el desafío de Camus, Morey nos invita a revisar un poco los caminos que Michelstaedter recorrió en sus últimos años de vida, entre 1908 y 1910, tiempo de escritura de su infinita Tesi di laurea. Nos recuerda que su amigo Enrico, aquel que estuvo en la génesis de su proyecto doctoral, le entregó el revolver que pondrá fin a sus días antes de partir hacia la Argentina, adentrándose en el mar, adentrándose en el desierto. Morey recalca algo concreto: Carlo, como bien dijimos, no vivió los horrores de la guerra, ni los fascismos, ni el comunismo, ni Auschwitz (Morey, 2014); no vio el nacimiento del Reich y las catexis familiaristas. Pero eso no es lo importante; lo importante es que conocía estos egoístas y mezquinos fenómenos, claramente retóricos. Así, su amigo Enrico Mreule tiene que vagar por un mundo que Carlo había vislumbrado gracias a Parménides, a Platón, a Schopenhauer y Buda: el buen discípulo es el que sigue.

\section{IV}

Arriesgarnos a trazar una hipótesis es algo descabellado, mezquino, cobarde, retórico. No obstante, también lo sería dejar pasar la oportunidad de añadir unas notas finales acerca del caso Michelstaedter, y, principalmente, del fenómeno del suicidio. Hay que aclarar que esto no se realiza por mor de aquellos que ya no pueden sentir sobre sí la mirada, sino para nosotros, que sabiendo 
que somos murientes todavía podemos mirar. Mirar. Nuevamente, theorein que trata de esquivar el prejuicio; a la vez que observa, muestra. Una buena palabra para describir este último acto es "misterio", imposibilidad -biológica y psicológica- de llegar a establecer una causa fehaciente. Cuando se habla del suicidio, se tiende a abordar ánimos extremos, ya sea reduccionistas o emergentistas, pues no hay forma de pensar el suicidio de manera simple, a no ser como un epifenómeno. Que Michelstaedter se haya suicidado queda en la anécdota, ya que esto no produce ninguna clase de archivo ni memoria. Probemos con una definición clara y concisa: suicida es el que no puede relatarnos su experiencia, aquel del que no hay rastro ni huella, el acólito solitario. Puede que la Vida - con "V" mayúscula - sea aquello perseguido por Michelstaedter. Sea como fuere, y para emparentarlo con el pensador del que hicimos uso al principio de este pequeño trabajo, Gilles Deleuze, quizá no se quitó la Vida. Es posible que ni el francés ni el goriziano hayan pensado en negación de Vida cuando acometieron el acto final. Quizá nuestra introspección alcance a decirnos esto: tratar de saber qué pasó, cómo pasó, por qué pasó es recrear una vez más la retórica, el juego de referencias que nos hermana (y enemista) como sociedad. Pero la máquina retórica siempre supone cierta violencia, ya sea política, descriptiva, valorativa o "filosófica". Quitar el absoluto del medio, o no hacer de la propia voluntad una mera voluntad-para, voluntad-sobre-medio, voluntad de absoluto. Al principio hablamos sobre los conceptos, esos ontológicos que se cansan, que son exhaustivos, que nosotros agotamos, y quizá sí tenga sentido volver sobre este personaje entrañable, a pesar de la distancia temporal, local y física, para vivir con él. Si la vida merece o no ser vivida, gran dilema; sin embargo, y lejos del Quietiv schopenhauereano de la música, digamos que por este rato no importa. Escribo esto en un contexto de pandemia, de cuarentena, de incertidumbre: no hay mejor época para vincularnos con el pasado y con el futuro. Revisionismo y opiniones por doquier, se juntan y articulan nuestro día a día, a la espera, quizá, de resoluciones míticas. Mito sobre mito, como es la retórica, no nos dejemos llevar por el mesianismo y recurramos a la idea doblemente utópica de Michelstaedter: hay que renunciar al nolugar, así como también a la retórica aristotélica de los topoi. Me disculpo por esta inclusión fugaz y sin excusa, pero 
somos, en definitiva, un peso que cae o un aeróstato que flota; que cae porque cae, que flota porque flota. No importa. Lo que hay que vencer en ambos casos es la gravedad.

\section{Referencias}

Ara, A. \& Magris, C. (1982) Trieste. Una identità di frontiera. Torino: Einaudi.

Benvegnù, D. (2016) "Toward a Minor Michelstaedter", en Italian Culture, n³4, 81-97.

Campailla, S. (2018) "Las primeras interpretaciones de Michelstaedter (1910-1916)" en Zibaldone, en Estudios Italianos, vol. VI, nำ, 51-62.

Campailla, S. (2010) II segreto di Nadia B. Venezia: Marsilio.

Campailla, S. (1974) A ferri corti con la vita. Gorizia: Comune di Gorizia.

Foucault, M. (1979) "Un plaisir si simple", en Dits et écrits.

La Rocca, C. (2011) “La persuasione (e l'oratoria)”, en Humanitas, no66, 811-835.

Magris (2012) Un altro mare. Milano: Il sole 24 ore.

Michelstaedter, C. (2010) Epistolario. A cura di Sergio Campailla. Milano: Adelphi.

Michelstaedter, C. (1995) La persuasione e la retorica. Milano: Adelphi.

Michelstaedter, C. (1958) Opere. Firenze: Sansoni.

Morey, M. (2014) “Sobre el suicidio lógico”, en Scientia Helmantica, n³, 56-70. 